\title{
Radiation-Induced Olfactory Neuroblastoma Following Treatment for NK/T-cell Lymphoma, Nasal Type
}

\author{
KOICHIRO MURAKI*, ETSUYO OGO*, GEN SUZUKI ${ }^{\dagger}$, HIROAKI SUEFUJ**, \\ HIDEHIRO ETO*, CHIYOKO TSUJI*, CHIKAYUKI HATTORI*, \\ YUSAKU MIYATA*, JUN AKIBA** AND TOSHI ABE* \\ * Department of Radiology, ** Department of Pathology, Kurume University School of Medicine, Kurume 830-0011, \\ + Department of Radiology, Kyoto Prefectural University of Medicine, Kyoto 602-8566, Japan \\ Received 22 October 2019, Accepted 12 February 2020 \\ J-STAGE advance publication 26 November 2021 \\ Edited by HIROHITO UMENO
}

\begin{abstract}
Summary: Radiation-induced olfactory neuroblastoma (ONB) is an uncommon neoplasm that is generally associated with a poor prognosis. We experienced an unusual case of ONB in a patient who had received previous radiation therapy for extranodal NK/T-cell lymphoma 15 years previously. To our knowledge, this is the first report of a patient with radiation-induced ONB obtaining a complete response $(\mathrm{CR})$ with radical re-irradiation alone. The purpose of this report is to discuss therapeutic strategies for radiation-induced ONB.

We report an unusual case of ONB suspected to be a radiation-induced neoplasm in a 33-year-old female who had received $30 \mathrm{~Gy}$ of irradiation for extranodal NK/T-cell lymphoma, nasal type (NTCL) 15 years earlier. In this case, the patient presented with nasal obstruction and frequent epistaxis. The patient was diagnosed with ONB based on left nasal biopsy findings. The surrounding normal tissues tolerance of nasal ONB radiation had to be limited, because the previously radiated NTCL was located adjacent to critical organs. We performed intensity modulated radiation therapy (IMRT), which could offer precise irradiation (60 Gy in 2 Gy daily fractions) while sparing critical tissues. The present case was treated with radiation therapy alone, whereas previously reported cases were treated with a combination of chemotherapy and radiation therapy. We treated radiation-induced OBN successfully with radical re-irradiation using IMRT alone and the patient has had no recurrence for 3 years.
\end{abstract}

Keywords olfactory neuroblastoma, NK/T-cell lymphoma, radiation-induced neoplasm, second neoplasm

\section{INTRODUCTION}

The treatment outcomes of patients with malignancies are improving because of recent advances in diagnostic and therapeutic modalities. However, the risk of second malignancies after radiation therapy is a problem of deep concern. Salvage therapy for second malignancies of head and neck after radiation therapy are often especially difficult, because of cosmetic factors due to surgery and tolerance of re-irradiated doses for normal tissues and radioresistance. We present an unusual case of radiation induced ONB occurring in a patient 15 years after undergoing radiation therapy for NTCL who was treated successfully with radical reirradiation using IMRT.

\section{CASE PRESENTATION}

An 18-year-old female was diagnosed with NTCL. She underwent chemotherapy (Vincristine, Adriamy-

Corresponding Author: Koichiro Muraki, Department of Radiology, Kurume University School of Medicine, 67 Asahi-machi, Kurume, Fukuoka 830-0011, Japan. Tel: +81-942-31-7576, Fax: +81-942-32-9405, E-mail: muraki_kouichirou@med.kurume-u.ac.jp

Abbreviations: 5-FU, 5-fluorouracil; ABMT, autologous bone marrow transplantation; ALL, acute lymphocytic leukemia; ANLL, acute nonlymphocytic leukemia; CBDCA, Carboplatin; CDDP, cisplatin; CPA, cyclophosphamide; CTx, chemotherapy; DFS, Disease-free survival; DLBCL, diffuse large B-cell lymphoma; DSS, Disease specific survival; DXR, Adriamycin; DXT, docetaxel; HN, head and neck; ICE, ifosfamide carboplatin etoposide; IMRT, Intensitymodulated radiation therapy; NTCL, natural killer/T-cell lymphoma; ONB, Olfactory neuroblastoma; RIS, Radiation-induced sarcomas; SBRT, Stereotactic body radiation therapy; SRS, Stereotactic radiosurgery; TBI, total body Irradiation; VP-16, etoposide; WBRT, Whole brain radiation therapy. 
cin, L-Asparaginase, Cytarabine, Methotrexate, etc.) and adjuvant radiation therapy for residual tumor, which consisted of $2 \mathrm{~Gy}$ in 15 fractions to a total dose of $30 \mathrm{~Gy}$ at our hospital.

Figure 1 showed the initial radiation field for residual NTCL at right nasal cavity after systemic chemotherapy. We used one field technique (anterior-posterior $[\mathrm{A}-\mathrm{P}])$. Optic chiasm and brainstem received 15 Gy and 25.5 Gy, respectively (FIg. 1).

Fifteen years after initial treatment, nasal endoscopy showed a polypoid mass filling the superior nasal cavity with bleeding (FIg. 2, FIg. 4a). Magnetic resonance imaging (MRI) showed a nasal septal mass within the left nasal cavity. The tumor was confined to the nasal cavity. The ethmoid sinus and skull base were free from tumor invasion (FIg. 2). We took a biopsy specimen using transnasal approach. Histologically, the tumor was an undifferentiated and highly cellular neoplasm that consisted of small round to oval

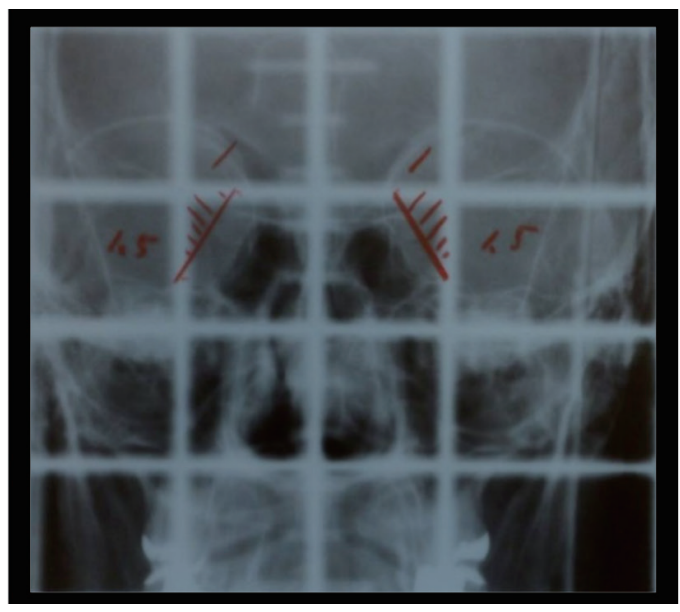

cells with hyperchromatic nuclei, a high nucleo-cytoplasmic ratio, many mitotic figures and perivascular pseudorosettes. The tumor was identified as a highgrade olfactory neuroblastoma with positive immunostaining for Chromogranin and Ki67/MIB-1 (FIg. 3 ). The primary NTCL that we examined was positive for Epstein-Barr virus encoded small RNA (EBER1) in situ hybridization, however EBER1was negative in this secondary ONB.

This case was classified as Kadish stage A and T1 according to the TNM staging system. The patient refused skull base surgery due to postoperative complication risk of cerebrospinal rhinorrhea and cosmetic concerns. She was prescribed 60 Gy in 2 Gy daily fractions. IMRT could deliver a definitive dose to the in-field second primary tumor, although the target volume was located to avoid the critical organs at risk such as the previously irradiated brainstem, optic chiasm and optic nerve (FIg. 5).

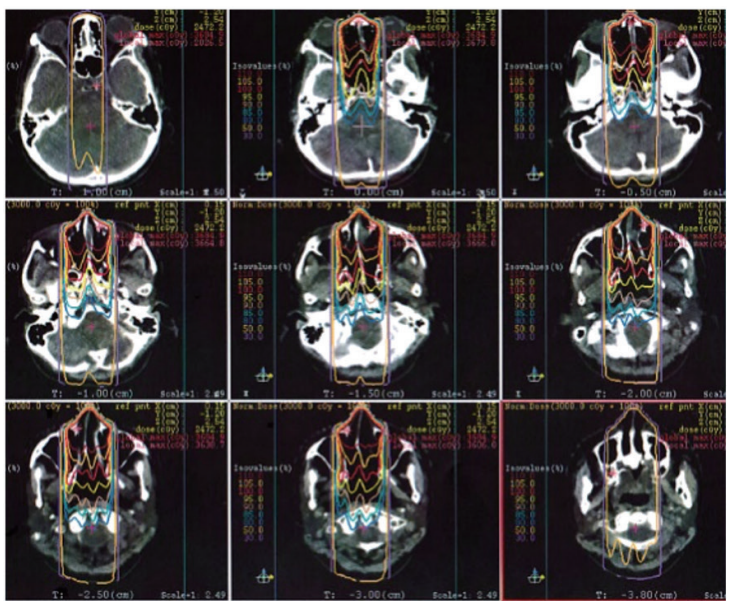

Fig. 1. We used one field technique (anterior-posterior[AP]). Optic chiasm and brainstem received 15 Gy to $25.5 \mathrm{~Gy}$, respectively.

(a)

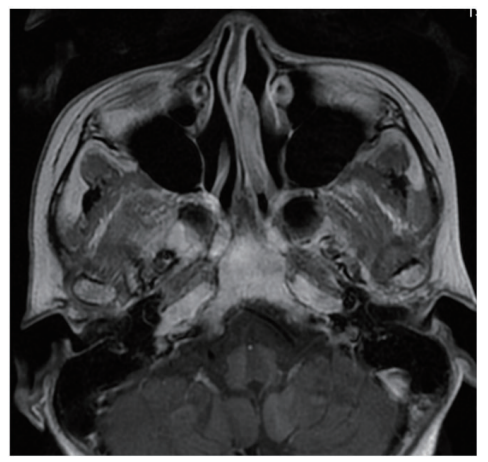

(b)

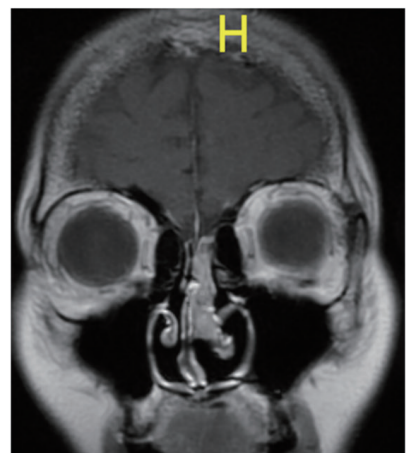

(c)

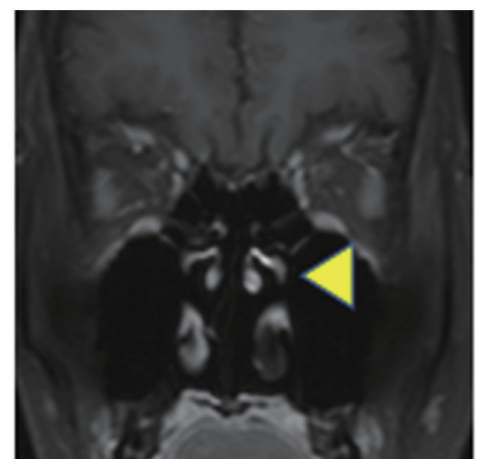

Fig. 2. MRI-T1WI contrast-enhanced (a) axial (b) coronal Tumor is located in the nasal cavity, without involvement of skull base or paranasal sinus. (a)(b) At 15 years after initial treatment.

(c) One month after secondary treatment, the tumor shrank and it is difficult to point out on MRI fat suppression T1WI-CE 

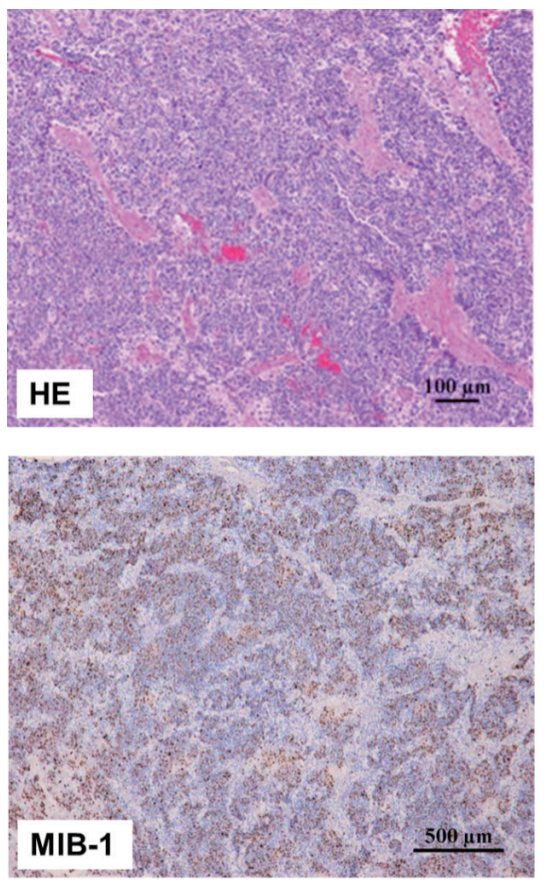
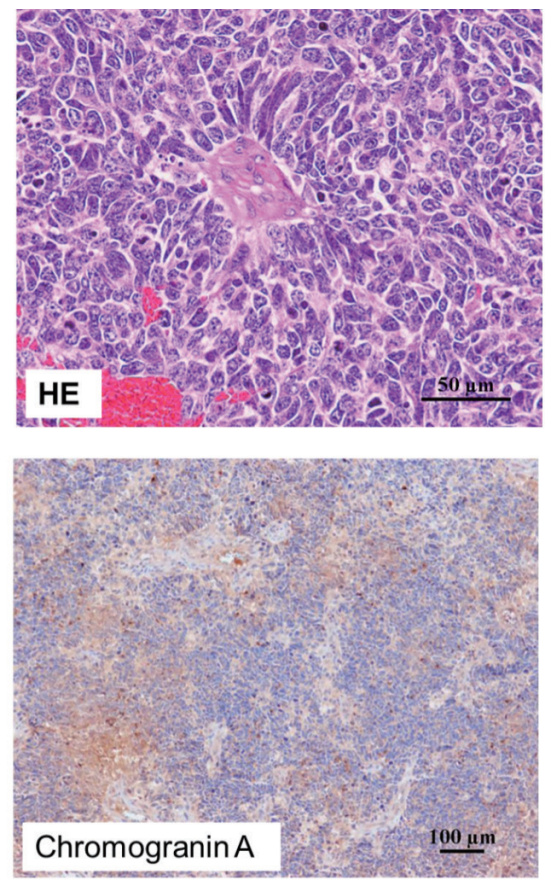

Fig. 3. Histopathological findings at the recurrence

The tumor was an undifferentiated and highly cellular neoplasm that consisted of small round to oval cells with hyperchromatic nuclei, a high nucleo-cytoplasmic ratio, many mitotic figures and perivascular pseudorosettes. The tumor was identified as a highgrade olfactory neuroblastoma with positive immunostaining for Chromogranin $\mathrm{A}$ and MIB-1 (a)

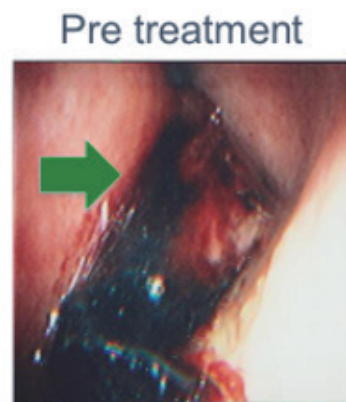

(b)

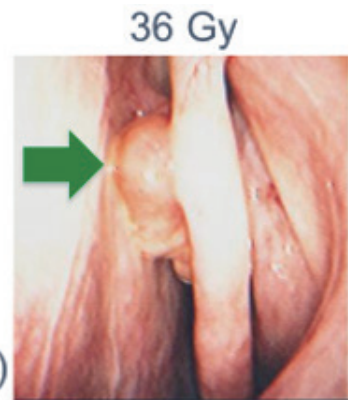

(c)
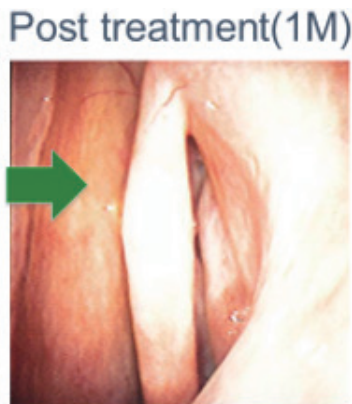

Fig. 4. (a) (c) The endoscopic findings of therapeutic courses on the left nasal cavity

(a) The nasal cavity was filled by tumor before secondary treatment.

(b) The tumor shrank at 36Gy irradiation.

(c) One month after IMRT treatment, the nasal cavity changed to normal mucus,

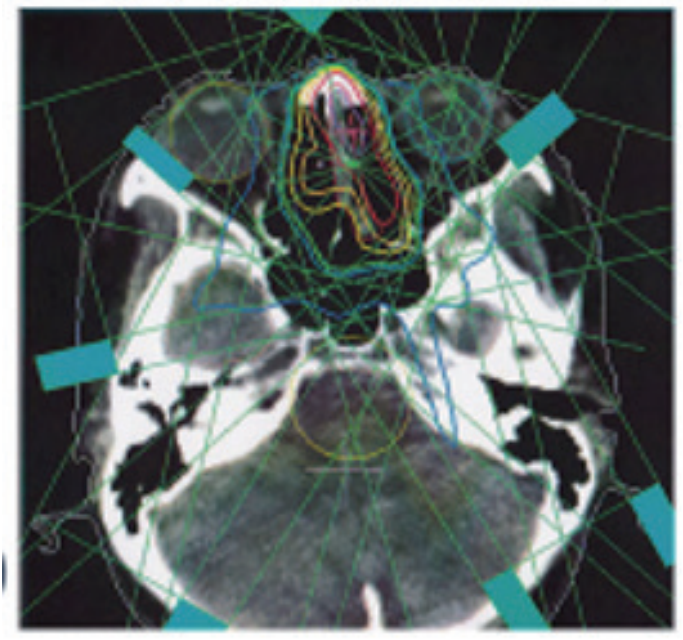

Fig. 5. IMRT was used to treat the secondary neoplasm. 
The patient has a stable scar from both diseases and no relapse 5 years after these severe treatments (FIg. 2c, FIg. 4 a-c).

\section{DISCUSSION}

$<$ NTCL $>$

The nasal natural killer (NK)/T-cell subtype of lymphoma is a distinct clinical entity characterized by expression of the NK-cell antigen CD56 [1-3]. Nasal NK/T-cell lymphoma is the most common subtype of primary nasal lymphoma, at least in Asian, Mexican and South American populations. Early stage disease tends to respond well to radiation therapy as reported by Li et al. [4] There was also an adequate response to initial treatment in our study. Unfortunately, ONB occurred in our present patient 15 years after undergoing the initial radiation therapy. The tumor is most often diagnosed with a chief complaint of bleeding and nasal obstruction on the affected side $[5,6]$. Our case had a chief complaint of nasal hemorrhage.

\section{$<\mathrm{ONB}>$}

ONB is an uncommon tumor of the head and neck. There are no randomized clinical trials to date to guide the treatment for ONB. Furthermore, reports on management of radiation-induced second primary ONB are scarce in the literature. Only five documented cases were reported, due to the rarity of the disease (Table 1). ONB accounts for about $3 \%$ of tumors identified within the nasal cavity, and arises from the olfactory mucosa of the cribriform plate, the upper one third of the nasal septum, and the upper surface of the superior turbinate. It often invades the subarachnoid spaces and leads to a high incidence of intracranial extension and commonly suffers a local recurrence [7-9]. All previously reported cases were female patients. Period to onset of secondary ONB after initial therapy was 9 years for 2 patients, 15 years for one patient, and more than 20 years in 3 patients. There were two patients with distant metastases. According to the Kadish classification, one patient was in stage A, two in stage B, three in stage $C[10]$. Dulguerov classification showed one in T1, two in T2, two in T3, and one in T4 [11]. Almost all patients were classified histological grade 3 or higher by Hyams [12].

In the management of treatment for secondary $\mathrm{ONB}$, one patient was treated with surgery and adjuvant stereotactic radiosurgery (SRS), one was treated with irradiation alone, one was treated with chemoradiotherapy and two received chemotherapy only. Four patients died due to disease progression and the other two patients remained alive without disease during the observational period. In particular, our case showed a complete response after radiation therapy (IMRT) alone.

Dulguerov [13] conducted a meta-analysis of esthesioneuroblastoma in studies published between 1990 and 2000, and found that overall (OS) and disease-free survival (DFS) at 5 years averaged 45 and

TABLE 1.

\begin{tabular}{|c|c|c|c|c|c|c|}
\hline & $\begin{array}{l}\text { Shinji K [21] } \\
2001\end{array}$ & $\begin{array}{l}\text { K.J. Park [22] } \\
2008\end{array}$ & $\begin{array}{c}\text { Gerard P.McVey [23] } \\
2009\end{array}$ & $\begin{array}{l}\text { V.Perez Garcia [24] } \\
\qquad 2011\end{array}$ & $\begin{array}{l}\text { Russel Kahmke [25] } \\
\qquad 2016\end{array}$ & $\begin{array}{l}\text { Our } \\
\text { case }\end{array}$ \\
\hline Age & 17 & 59 & 36 & 43 & 49 & 33 \\
\hline Sex & $\mathrm{F}$ & $\mathrm{F}$ & $\mathrm{F}$ & $\mathrm{F}$ & $\mathrm{F}$ & $\mathrm{F}$ \\
\hline $\begin{array}{l}\text { Initial } \\
\text { primary }\end{array}$ & ALL/ANLL & $\begin{array}{l}\text { pituitary } \\
\text { adenoma }\end{array}$ & $\begin{array}{l}\text { DLBCL } \\
\text { (lt.tonsil) }\end{array}$ & $\begin{array}{l}\text { Astrocytoma } \\
\text { (gradeII) }\end{array}$ & $\begin{array}{l}\text { non-Hodgkin } \\
\text { Lymphoma } \\
\text { (stage 4) }\end{array}$ & $\begin{array}{c}\text { NK/Tcell } \\
\text { lymphoma } \\
\text { (rt.nasal cavity) }\end{array}$ \\
\hline $\begin{array}{l}\text { Initial } \\
\text { treatment }\end{array}$ & $\begin{array}{c}\text { TBI12Gy/6fr. } \\
\text { WBRT24Gy } \\
\text { ABMT }\end{array}$ & $\begin{array}{c}\text { subtotal } \\
\text { removal } \\
54 \mathrm{~Gy} / 30 \mathrm{fr} .\end{array}$ & $\begin{array}{l}\text { HN:60Gy/30fr. } \\
\text { Spine:30Gy/10fr. }\end{array}$ & $\begin{array}{c}\text { RT:58Gy } \\
\text { (WBRT40Gy+ } \\
\text { local18Gy) }\end{array}$ & WBRT24Gy & $\begin{array}{c}\text { 30Gy/15fr. }+ \\
\text { CTx }\end{array}$ \\
\hline $\begin{array}{l}\text { Period since } \\
\text { initial therapy }\end{array}$ & $9 y$ & $20 y$ & $25 y$ & $9 y$ & $23 y$ & $15 y$ \\
\hline Kadish & B & $\mathrm{C}$ & B & $\mathrm{C}$ & $\mathrm{C}$ & A \\
\hline Dulguerov & T2M1(BONE) & $\mathrm{T} 4$ & T2N1M1(PUL) & $\mathrm{T} 3$ & $\mathrm{~T} 3$ & $\mathrm{~T} 1$ \\
\hline Hyams & - & 4 & $3-4$ & 4 & 3 & 4 \\
\hline $\begin{array}{c}\text { Chemotherapy } \\
\text { /Surgery }\end{array}$ & $\mathrm{CPA}+\mathrm{DXR}$ & $\begin{array}{c}\text { ICE } \\
\text { surgery }\end{array}$ & $\mathrm{CBCDA}+\mathrm{VP}-16$ & DXT,CDDP,5-FU & $\begin{array}{l}\text { skull base } \\
\text { surgery }\end{array}$ & - \\
\hline $\begin{array}{c}\text { Prescription } \\
\text { Dose } \\
\text { outcome }\end{array}$ & $\begin{array}{c}- \\
\operatorname{died}(11 \mathrm{~m})\end{array}$ & $\begin{array}{c}- \\
\text { alive(3y) }\end{array}$ & $\begin{array}{c}- \\
\operatorname{died}(2 \mathrm{w})\end{array}$ & $\begin{array}{c}\text { RT } \\
50 \mathrm{~Gy} / 25 \mathrm{fr} . \\
\operatorname{died}(1 \mathrm{y})\end{array}$ & $\begin{array}{c}\text { SRT } \\
25 \mathrm{~Gy} / 5 \mathrm{fr} . \times 2 \\
\operatorname{died}(1 \mathrm{y})\end{array}$ & $\begin{array}{c}\text { IMRT } \\
\text { 60Gy/30fr. } \\
\text { alive(3y) }\end{array}$ \\
\hline
\end{tabular}


$41 \%$, respectively. They established tumor stage (Kadish or Dulguerov classification), histopathologic grade (Hyam's classification), and treatment modality such as surgery with or without adjuvant therapy as the important factors in disease specific survival (DSS). They showed significantly better 5 -year survival for Kadish stage A tumors (72\%) compared to stage B (59\%) or stage C (47\%) [13]. The modified Kadish classification system predicted DFS more accurately than the Dulguerov classification system ( $\mathrm{P}=0.04)$ [14]. The modified Kadish classification system is as follows, stage A; tumor is limited to the nasal cavity, stage B; tumor is in the nasal cavity and extends into the paranasal sinuses, stage $\mathrm{C}$; tumor extends beyond the nasal cavity and paranasal sinuses, involving the cribriform lamina, the skull base, the orbit or intracranial cavity, stage D; tumor with distant metastases. In our paper, we used the modified Kadish system. Banuchi [15] reported that the 10 year disease free survival rates were $69 \%$ for Kadish stage A, 56\% for stage B, $46 \%$ for stage C, and $0 \%$ for stage D.

\section{$<$ Radiation Therapy $>$}

Radiation therapy alone has been reported to lead to unsatisfactory outcomes because ONB is a malignant tumor which grows both locoregionally and distantly. Therefore, multidisciplinary treatment for ONB including surgery, chemotherapy and radiation therapy is the most frequently used approach. However, the ideal treatment modality remains controversial because of its rarity. Gruber reported that radiation therapy alone was not considered a definitive therapy [16]. However, Elkon [5] resulted that irradiation alone was equivalent to surgery alone and combination therapy in early-stage ONB, especially in the cribriform plate with little or no bony destruction in Kadish stage A [17]. Particle beam therapy can allow a more localized delivery of the radiation dose. Heavy ion therapy is expected to be especially effective in any malignant cells, and can have benefit in photon therapy resistant malignant cells. Therefore, particle beam therapy may be a useful therapeutic modality for ONBs.

However, the Japanese national medical insurance did not cover particle beam therapy at the time the present patient was being treated for ONB.

\section{$<$ ENI: elective-nodal irradiation $>$}

A retrospective study by Jiang [18] et al identified 71 patients without lymph node metastases (N0). Among the 65 patients treated with adjuvant radiation therapy, 44 received radiation to the tumor bed alone $(68 \%)$ and 21 patients (32\%) received additional elec- tive-nodal irradiation(ENI). ENI typically included the retropharyngeal, level IB and II nodes. The authors reported that only $7.7 \%$ of the non-ENI patients who developed neck recurrence had Kadish stage A/B disease. This corresponded to a neck failure rate of $10 \%$ among stage $\mathrm{A} / \mathrm{B}$ patients compared to $31 \%$ of stage $\mathrm{C}$ patients who did not have ENI. They concluded that the benefit of ENI was in younger patients who were presented with stage $\mathrm{C}$ disease.

\section{$<$ Secondary cancer $>$}

Our patient, who was Kadish stage A and relatively young, refused surgery due to postoperative complication risk and for cosmetic reasons. Chemotherapy was an unmanageable indication because of a history of hemorrhagic cystitis and severe renal dysfunction. She received IMRT alone with a localized irradiation dose of $60 \mathrm{~Gy}$ in 30 fractions at five fractions per week to clinical target volume encompassing gross tumor with $0.5-1 \mathrm{~cm}$ circumferential and anatomically based margins. Avoidance constraints were typically set as low as possible for previously irradiated brainstem, optic chiasm and optic nerve. IMRT could deliver full dose to the in-field second primary tumor.

Radiation-induced sarcomas (RIS) of the head and neck following radiation therapy for nasopharyngeal carcinoma are even less common, with an occurrence in adults of less than $0.5 \%$ in various situations. To detect an RIS at an earlier stage, the oncologist should perform regular physical examinations, and the radiologist should be aware of the common radiological appearances, which can be scrutinized on follow-up scans, especially among younger patients.

Yang [19] reported on patients with RIS in the head and neck following radiation therapy for nasopharyngeal carcinoma identified from a review of the histological and radiological results from December 1998 to September 2012. The most common origin sites of RIS were the maxillary sinus (29\%), neck $(20 \%)$ and mandibular ramus $(16 \%)$. The histological group was osteosarcoma (35\%), fibrosarcoma (32\%) and undifferentiated pleomorphic sarcoma (12\%). The clinically determined site of RIS was superficial (cutaneous or subcutaneous) in 57\% and deep in $43 \%$. As a result, our case is very rare both for its occurrence and its re-irradiation status outcome.

Cacicedo [20] reviewed the role of re-irradiation of secondary and recurrent head and neck carcinomas. Although his research mainly targeted squamous cell carcinoma, he suggested 15 criteria as treatment guidelines. We selected the following 8 items from the 15 criteria for our report; 
(1) Re-irradiation with an interval of at least 6 months after the previous course of radiation therapy has been described. However, a longer interval is preferred (1 year or more)

(2) Regarding tumor size, small volumes are preferable $\left(<30 \mathrm{~cm}^{3}\right)$. Re-irradiation of bulky tumors must be very cautiously evaluated $\left(>60 \mathrm{~cm}^{3}\right)$

(3) True second primary tumors have better prognoses than recurrences

(4) Tumors arising in the nasopharynx and larynx are good candidates, compared to other tumor locations (hypopharynx)

(5) Perform an exhaustive analysis of the previous treatment portals and dose distribution. Patients with previous doses (in the recurrence area) $<50$ Gy are preferable (higher risk if $>60-70 \mathrm{~Gy}$ )

(6) Doses of $>60$ Gy (approximately) are recommended to achieve greater local control

(7) No cases of myelopathy have been reported for cumulative doses $<60$ Gy in 2 Gy equivalent doses

(8) IMRT or SBRT (stereotactic body radiation therapy) techniques are preferable for reducing treatment-related toxicity (alone or in combination with chemotherapy or cetuximab)

Our patient fulfills most of the above criteria. This is a rare case that remains free of both disease and severe morbidity at 5 years follow-up.

Re-irradiation for radiation-induced neoplasm is a challenging treatment. After initial radiation therapy, the normal tissue tolerance is instrumental as regards adverse events. Thus, we should carefully consider indications for treatment strategy.

\section{CONCLUSION}

We report a rare case of ONB suspected to be a radiation-induced neoplasm that evolved after treatment for NK/T cell lymphoma. The treatment options for radiation-induced cancer are limited. The use of IMRT for re-irradiation of secondary primary cancer is expected to improve local control and survival. We must follow re-irradiation related adverse events carefully in the present case, because of the high radiation doses administered to her nasal cavity.

\section{DECLARATIONS}

ETHICS APPROVAL AND CONSENT TO PARTICIPATE: Written informed consent was obtained from the patient and institutional ethics board for submission of this Case report.

CONSENT FOR PUBLICATION: Written informed consent was obtained from the patient and institutional ethics board for publication of this Case report and any accompanying images.

AVAILABILITY OF DATA AND MATERIAL: A copy of the written consent is available for review by the Editor-in-Chief of this journal.

COMPETING INTERESTS: The authors declare that they have no competing interests.

FUNDING: The authors have no funding declared.

ACKNOWLEDGEMENTS: Not applicable

\section{AUTHORS' CONTRIBUTIONS:}

Guarantor of the integrity of the study: KM.

Study concepts: KM and GS.

Study design: KM.

Definition of intellectual content: KM and EO.

Literature research: KM and GS.

Clinical studies: KM and EO.

Data acquisition: KM.

Data analysis: KM and EO.

Statistical analysis: KM and EO.

Manuscript preparation: KM.

Manuscript review: EO.

All authors read and approved the final manuscript.

Manuscript English language editing: EO.

\section{REFERENCES}

1. Kim WS, Song SY, Ahn YC, Ko YH, Baek CH et al. CHOP followed by involved field radiation: Is it optimal for localized nasal natural killer/T-cell lymphoma? Ann Oncol 2001; 12:349-352.

2. Cheung MM, Chan JK, Lau WH, Foo W, Chan PT et al. Primary non-Hodgkin's lymphoma of the nose and nasopharynx: Clinical features, tumor immunophenotype, and treatment outcome in 113 patients. J Clin Oncol 1998; 16:70-77.

3. Kwong YL, Chan AC, Liang R, Chiang AK, Chim CS et al. CD56+ NK lymphomas: clinicopathological features and prognosis. Br J Haematol 1997; 97:821-829.

4. Li YX, Yao B, Jin J, Wang WH, Liu YP et al. Radiotherapy as primary treatment for stage IE and IIE nasal natural killer/T-cell lymphoma. J Clin Oncol 2006; 24:181-189.

5. Elkon D, Hightower SI, Lim ML, Cantrell RW, and Constable WC. Esthesioneuroblastoma. Cancer 1979; 44:1087-1094.

6. Spaulding CA, Kranyak MS, Constable WC and Stewart FM. Esthesioneuroblastoma: a comparison of two treatment eras. Int J Radiat Oncol Biol Phys 1988; 15:581-590.

7. Chao KS, Kaplan C, Simpson JR, Haughey B, Spector GJ et al. Esthesioneuroblastoma: the impact of treatment modality. Head Neck 2001; 23:749-757.

8. Platek ME. Merzianu M, Mashtare TL, Popat SR, Rigual $\mathrm{NR}$ et al. Improved survival following surgery and radiation therapy for olfactory neuroblastoma: analysis of the 
SEER database. Radiat Oncol 2011; 6:41.

9. Patel SG, See AC, Williamson PA, Archer DJ, and Evans PH. RADIATION INDUCED SARCOMA OF THE HEAD AND NECK. Head Neck 1999; 21:346-354.

10. Kadish S, Goodman M, Wang CC. OLFACTORY NEUROBLASTOMA: A Clinical Analysis of 17 Cases. Cancer 1976; 37:1571-1576.

11. Dulguerov P, Calcaterra T. Esthesioneuroblastoma: The UCLA Experience 1970-1990. Laryngoscope 1992; 102:843-849.

12. Hyams VJ, Batsakis JG, and Michaels. Tumors of the Upper Respiratory Tract and Ear. In: Hartmann WH (ed). Atlas of Tumor Pathology. 2nd series. Fascicle 25. Armed Forces Institute of Pathology. Washington, pp 240-248, 1998.

13. Dulguerov P, Allal AS, Calcaterra TC. Esthesioneuroblastoma: a meta-analysis and review. Lancet Oncol 2001; 2:683-690.

14. Song CM, Won TB, Lee CH, Kim DY, and Rhee CS. Treatment Modalities and Outcomes of Olfactory Neuroblastoma. Laryngoscope 2012; 122:2389-2395.

15. Banuchi VE, Dooley L, Lee NY, Pfister DG, and McBride S. Patterns of Regional and Distant Metastasis in Esthesioneuroblastoma. Laryngoscope 2016; 126:15561561.

16. Gruber G, Laedrach K, Baumert B, Caversaccio M, Raveh $\mathrm{J}$ et al. Esthesioneuroblastoma: irradiation alone and surgery alone are not enough. Int $\mathbf{J}$ Radiat Oncol Biol Phys 2002; 54:486-491.

17. Benfari G, Fusconi M, Ciofalo A, Gallo A, Altissimi G et al. Radiotherapy alone for local tumour control in esthesioneuroblastoma. Acta Otorhinolaryngol Ital 2008; 28:292-
297.

18. Jiang W, Mohamed AS, Fuller CD, Kim BYS, Tang C et al. The role of elective nodal irradiation for esthesioneuroblastoma patients with clinically negative neck. Pract Radiat Oncol. 2016; 6:241-247.

19. Yang Q, Mo Y, Zhao Q, Ban X, He M et al. Radiationinduced sarcomas of the head and neck in post-radiation nasopharyngeal carcinoma. Radiol Med 2017; 122:53-60.

20. Cacicedo J, Navarro A, Alongi F, Gómez de Iturriaga A, Del Hoyo $\mathrm{O}$ et al. The role of re-irradiation of secondary and recurrent head and neck carcinomas. Is it a potentially curative treatment? A practical approach. Cancer Treat Rev 2014; 40:178-189.

21. Kounami S, Douno S, Matsubara H, Takayama J, and Ohira M. OLFACTORY NEUROBLASTOMA AS A SECOND MALIGNANT NEOPLASM In A PATIENT PREVIOUSLY TREATED FOR CHILDHOOD ACUTE LEUKEMIA. Pediatr Hematol Oncol 2001; 18:459-463.

22. Park KJ, Kang SH, Lee HG, and Chung YG. Olfactory neuroblastoma following treatment for pituitary adenoma. J Neurooncol 2008; 90:237-241.

23. McVey GP, Power DG, Aherne NJ, Gibbons D, and Carney DN. Post irradiation olfactory neuroblastoma (esthesioneuroblastoma): A case report and up to date review. Acta Oncol 2009; 48:937-940.

24. Perez Garcia V, and Martinez Izquierdo Mde L. Radiationinduced olfactory neuroblastoma: a new etiology is possible. Oral Maxillofac Surg 2011; 15:71-77.

25. Kahmke RR, Van Arnam J, and Puscas L. Case Report. Radiation-Induced Olfactory Neuroblastoma. Ann Otolaryngol Rhinol 2016; 3:1111. 